\title{
A Frameshift Mutation in the Human Apolipoprotein A-I Gene Causes High Density Lipoprotein Deficiency, Partial Lecithin: Cholesterol-Acyltransferase Deficiency, and Corneal Opacities
}

\author{
Harald Funke," Arnold von Eckardstein," P. Haydn Pritchard, ${ }^{\ddagger}$ Michael Karas," John J. Albers," and Gerd Assmann" \\ With the technical assistance of Andrea Reckwerth and Sabine Welp \\ *Institut für Klinische Chemie und Laboratoriumsmedizin, Universität Münster, Albert-Schweitzer-Straße 33, 4400 Münster, FRG; \\ ${ }^{\ddagger}$ Lipid Research Group, Department of Pathology, University of British Columbia, Vancouver, Canada; ${ }^{\S}$ Institut für Medizinische Physik, \\ Universität Münster, FRG; 'University of Washington, Seattle, Washington 98105; and 'Institut für Arterioskleroseforschung an der \\ Universität Münster, FRG
}

\begin{abstract}
Epidemiologic data of recent years have identified an important role of HDL deficiency in the etiology of atherosclerosis. Biochemical data suggest that some of these deficiencies may be a consequence of defects in the structural genes of HDL apolipoproteins or of plasma enzymes that modify HDL. We analyzed the genetic defect in a 42-yr-old patient suffering from corneal opacities and complete absence of HDL cholesterol but not of coronary artery disease, thus clinically resembling fish eye disease. The observation of an abnormal immunoblot banding pattern of apolipoprotein A-I (apo A-I) and of reduced lecithin: cholesterol acyltransferase (LCAT) activity in plasma led to sequence analysis of the genes for apo A-I and LCAT in this patient and his family. Direct sequencing of polymerase chain reaction amplified DNA segments containing the exons of the candidate genes, resulted in the identification of a frameshift mutation in apo A-I while the LCAT sequence was identical to the wild type. The apo A-I mutation was predictive for an extensive alteration of the $\mathrm{COOH}$-terminal sequence of the encoded protein. Evidence for the release of this mutant protein into the plasma compartment and for the absence of normal apo A-I was derived from ultraviolet laser desorption/ionization mass spectrometry analysis. Our results suggest that a defective apo A-I is the causative defect in this case of HDL deficiency with corneal opacities. (J. Clin. Invest. 1991. 87:371376.) Key words: PCR amplification • direct sequencing • laser mass spectrometry - gene analysis - restriction site polymorphism
\end{abstract}

Address for reprint requests: Dr. Harald Funke, Institut für Klinische Chemie und Laboratoriumsmedizin, Universität Münster, AlbertSchweitzer-Straße 33, 4400 Münster, FRG.

Received for publication 20 July 1990 and in revised form 27 Sept 1990.

J. Clin. Invest.

(c) The American Society for Clinical Investigation, Inc. $0021-9738 / 91 / 01 / 0371 / 06 \quad \$ 2.00$

Volume 87, January 1991, 371-376

\section{Introduction}

HDL, their major protein component apolipoprotein A-I (apo A-I $)^{1}$ and the cholesterol esterifying enzyme lecithin: cholesterol-acyltransferase (LCAT) have been demonstrated to play important roles in the removal of excess cellular cholesterol in a process termed reverse cholesterol transport (1-4). Genetic or environmental impairments of this process are thought to provide the basis for the observed association between reduced plasma HDL cholesterol concentrations and premature onset of atherosclerosis (reviewed in reference 5). Although prospective epidemiologic studies have identified HDL cholesterol to be one of the most predictive risk indicators, there are rare examples of virtually complete HDL deficiencies that are not associated with an increased risk, e.g., Tangier disease (2), some cases of familiar LCAT deficiency (3), and fish eye disease (FED) (3). This paradox addresses the need for a more detailed understanding of the role of HDL in reverse cholesterol transport as well as for a precise classification system for HDL deficiencies. Knowledge of the underlying defects in these conditions will facilitate both. We report here the genetic defect underlying an HDL-deficiency syndrome that is clinically and biochemically similar to $\operatorname{FED}(6,7)$.

\section{Methods}

Subject. The patient is an otherwise health 42-yr-old man who was investigated because of massive corneal clouding which resembled that described for FED patients $(3,6,7)$. Inside of arcus lipoides, the opacifcation covered most of the irises of both eyes and was patchy as well as confluent. Lipid parameters are documented in Table I. All other laboratory findings were normal. The patient did not suffer from any signs of coronary heart disease and the ECG did not reveal any signs of coronary insufficiency even upon work at $250 \mathrm{~W}$. Family history was not indicative for any increased prevalence of myocardial infarction. There was no indication of inbreeding in the family, as the parents of

1. Abbreviations used in this paper: apo, apolipoprotein; CAD, coronary artery disease; CER, cholesterol esterification rate; FED, fish eye disease; IEF, isoelectric focusing; LCAT, lecithin: cholesterol acyltransferase; PCR, polymerase chain reaction; UV-LDI-MS, ultraviolet laser desorption/ionization mass spectrometry. 
Table I. Lipid Values, Apo A-I Concentrations and LCAT Mass and Activities in a Family with HDL Deficiency, Partial LCAT Deficiency, and Corneal Opacifications

\begin{tabular}{|c|c|c|c|c|c|c|c|c|c|}
\hline Subjects & Sex/age & Cholesterol & Triglyceride & HDL cholesterol & LDL cholesterol & Apo A-I & CER & LCAT activity & LCAT mass \\
\hline & & & & $m g / d l$ & & & \multicolumn{2}{|c|}{ nmol/h per ml } & $g / m l$ \\
\hline \multicolumn{10}{|c|}{ Homozygote } \\
\hline Ile & $\mathrm{m} / 42$ & 243 & 196 & 0 & 203 & 3 & 31 & 12.5 & 2.88 \\
\hline \multicolumn{10}{|c|}{ Heterozygotes } \\
\hline Ib & $f / 72$ & 266 & 182 & 29 & 201 & 99 & 125 & 20.6 & 5.02 \\
\hline IIIa & $\mathrm{f} / 8$ & 202 & 222 & 26 & 132 & 80 & 158 & 26.1 & 4.38 \\
\hline IIIb & $f / 6$ & 163 & 117 & 31 & 118 & 87 & 129 & 19.5 & 4.44 \\
\hline IIIIc & $\mathrm{m} / 4$ & 187 & 100 & 29 & 128 & 72 & 159 & 29.1 & 5.41 \\
\hline Mean \pm SD & & $205 \pm 44$ & $155 \pm 56$ & $29 \pm 2$ & $145 \pm 38$ & $85 \pm 11$ & $143 \pm 18$ & $23.8 \pm 4.5$ & $4.81 \pm 0.49$ \\
\hline \multicolumn{10}{|l|}{ Normals } \\
\hline IIa & $\mathrm{m} / 50$ & 272 & 172 & 41 & 197 & 138 & 220 & 27.2 & 7.32 \\
\hline IIb & $\mathrm{m} / 49$ & 263 & 115 & 35 & 160 & 118 & 138 & n.d. & n.d. \\
\hline IIc & $\mathrm{m} / 44$ & 241 & 205 & 39 & 173 & 152 & 180 & 27.0 & 5.84 \\
\hline IId & $\mathrm{f} / 40$ & 185 & 110 & 73 & 93 & 170 & 95 & 30.4 & 4.69 \\
\hline Mean \pm SD & & $240 \pm 34$ & $151 \pm 40$ & $47 \pm 15^{*}$ & $156 \pm 39$ & $145 \pm 19^{\ddagger}$ & $158 \pm 47$ & $28.2 \pm 1.6$ & $5.95 \pm 1.08$ \\
\hline
\end{tabular}

$P$ was calculated by Student's $t$ test; comparisons were made between heterozygotes and normals. ${ }^{*} P<0.05 ;{ }^{\ddagger} P<0.001$.

the homozygous patient originated from different parts of Germany. The studies were performed with the proband's consent.

Quantitation of lipids, apolipoproteins, and LCAT-activities and -mass. Concentrations of cholesterol and triglycerides were determined using an autoanalyzer (Hitachi/Boehringer Mannheim, Mannheim, FRG). LDL cholesterol was determined by the method of Friedewald (8). HDL cholesterol was analyzed after precipitation with phosphotungstic acid/ $\mathrm{MgCl}_{2}$. Apo A-I was quantified by turbidimetry as described (9). The rate of cholesterol esterification in plasma was determined by two methods. The cholesterol esterification rate (CER) reflects the esterification of endogenous cholesterol and was determined by the method of Dobiasova (10). An exogenous substrate assay using artificial proteoliposomes that contain normal apo A-I as well as phosphatidylcholine and unesterified $\left[{ }^{3} \mathrm{H}\right]$ cholesterol was used to measure plasma LCAT activity in vitro (11). LCAT mass was determined immunologically by a previously described method (12).

Electrophoretic procedures. For isoelectric focusing (IEF) of apo A-I and apo A-II, $2 \mu \mathrm{l}$ (controls) or $10 \mu \mathrm{l}$ (HDL-deficient probands) of plasma or apolipoproteins isolated from $1 \mathrm{ml}$ of VLDL, LDL, or HDL were incubated with $50 \mu \mathrm{l}$ of a buffer containing $0.01 \mathrm{M}$ Tris $\mathrm{HCl}(\mathrm{pH}$ 8.2 ), $1 \%$ decylsulfate, $2.5 \%$ carrier ampholytes in the presence (reductive conditions) or absence of $200 \mathrm{mM}$ dithiotheritol. Samples were separated by IEF in a gradient ranging from $\mathrm{pH} 3$ to $\mathrm{pH} 7$ (13). After electroblotting to nitroucellulose (14), a mixture of monoclonal antibodies raised against apo A-I (provided by L. Curtiss, La Jolla, CA, E. Marcovina, Milano, Italy, and J. C. Fruchart, Lille, France) was bound to the immobilized antigen. Biotinylated anti-mouse $\operatorname{lgG}$ and streptavidin-coupled peroxidase were used for visualization. Apo A-II was detected with a polyclonal goat anti-apo A-II antiserum by basically the same procedure.

Gene sequencing. Genomic DNA was isolated from peripheral blood cells of the proband, his family members, and a series of normal controls. 21 bases long oligonucleotides complementary to the apo A-I (see Fig. 3) and LCAT cDNAs were used as primers for amplification by the polymerase chain reaction (PCR) (15). The amplification reaction was carried out in 50- $\mu$ l buffer, as recommended by the supplier of the Taq polymerase (AmpliTaq; Perkin-Elmer/Cetus), and contained $0.5-1 \mu \mathrm{g}$ DNA, $200 \mu \mathrm{M}$ dNTPs and $0.1 \mu \mathrm{M}$ primers. Initial denaturation at $100^{\circ} \mathrm{C}$ for $10 \mathrm{~min}$ was followed by the addition of $3 \mathrm{U}$ Taq polymerase and $30 \mathrm{cycles}$ of $96^{\circ} \mathrm{C}(2 \mathrm{~min}), 60^{\circ} \mathrm{C}(1 \mathrm{~min})$, and $70^{\circ} \mathrm{C}(1$ $\mathrm{min}$ ) incubations. Product purification was carried out by electrophoresis in $4 \%$ Nusieve agarose (FMC Corp.); DNA of the expected size was cut out of the gel and electroeluted in $0.5 \times$ TAE for $1.25-1.5 \mathrm{~h}$ at 200 $\mathrm{V}$. DNA was desalted and concentrated to $70 \mu \mathrm{l}$ by ultrafiltration in Centricon X-100 tubes (Amicon Corp.). Centrifugation was conducted 3 times at $5,000 \mathrm{rpm}$ for $20 \mathrm{~min}$ with the addition of $2 \mathrm{ml}$ of water between runs. Single-strand DNA was produced from the purified fragment by the method of Gyllenstein and Erlich (16) using the same reaction and purification scheme as above. Primer concentration was $0.1 \mu \mathrm{M}$; a second primer was not used. After phenol extraction and $\mathrm{LiCl} /$ ethanol precipitation, sequencing was carried out on single-strand or double-strand templates, using T7 polymerase (Pharmacia, Inc., Freiburg, FRG) following the protocol of the supplier. Labeling times varied between 0.5 and $10 \mathrm{~min}$. After termination, the sample volume was reduced to $6 \mu \mathrm{l}$ in an evaporation centrifuge; half of it was applied to the sequencing gel ( $5 \%$ polyacrylamide with $29: 1$ cross-linking in $135 \mathrm{mM}$ TRIS, $45 \mathrm{mM}$ boric acid, $2.5 \mathrm{mM}$ EDTA; bind silan was used on both plates). Cel II RFLPs were determined in PCR amplified apo A-I DNA using primers 5 and 10 . Incubation conditions were as recommended by the supplier (Boehringer Mannheim, Inc.).

Preparation of apo A-I. LDL apolipoproteins isolated from a 1-liter plasmapheresis of the homozygous patient by sequential ultracentrifugation $(d=1.019-1.063 \mathrm{~kg} /$ liter $)$ and subsequent delipidation were separated by preparative IEF in an immobilized pH gradient, $\mathrm{pH}$ 5-7. The protein focusing at the position of normal apo A-I was electroeluted from the gel, dialyzed, and purified by reversed phase HPLC (17)

Mass spectrometry. Lyophilized apo A-I was resolubilized in an aqueous solution of $0.05 \mathrm{M}$ nicotinic acid and analyzed by ultraviolet laser desorption/ionization mass spectrometry (UV-LDI-MS) using a Q-switched (10 ns), frequency-quadrupled Nd-Yag laser at a wavelength of $266 \mathrm{~nm}$ of a reflector-type time-of-flight mass spectrometer (LAMMA 1000; Leybold-Heraeus, Köln) (18).

\section{Results}

We investigated a 42-yr-old patient and his family (Fig. 1) who suffered from massive corneal opacifications, complete absence of HDL, and half-normal LCAT activity (Table I). Clinically and biochemically the patient resembled a phenotype 


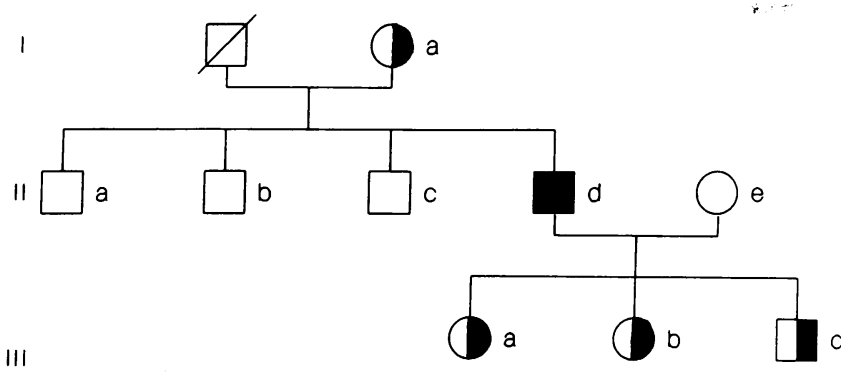

Figure 1. Pedigree of the family suffering from HDL deficiency with corneal opacifications and partial LCAT deficiency. Heterozygous and homozygous genotypes are indicated with standard symbols.

much like those of Swedish and Canadian cases of $\operatorname{FED}(6,7)$. However, while LCAT activity is near absent in FED (7), in our patient there was a reduction to only about one-third of normal LCAT activity. It was normal in the heterozygotes. In addition, the simultaneous decrease in the CER and in LCAT activity confirms that this disorder represents an entity that is distinct from FED (Table I). Family analysis suggested that the patient is homozygous for a vertically transmitted gene defect in which the heterozygous phenotype is characterized by half-normal plasma HDL cholesterol and apo A-I concentrations (Table I).

Isoelectric focusing and subsequent immunoblot analysis of the patient's plasma and isolated lipoprotein fractions showed normal as well as atypical banding for apolipoproteins A-I and A-II (Fig. 2). Conversely, the banding pattern of apo C-III and apo A-IV were normal (not shown). These two apoproteins are major constituents of HDL and along with apo A-I are the gene products of the APOLP1 locus (19). In contrast to normal controls, most of the patient's apo A-I immunoreactive bands were found in LDL and in the lipoprotein-depleted infranatant after ultracentrifugation at a density of $1.21 \mathrm{~g} / \mathrm{ml}$. The number of apo A-I immunoreactive bands and their positions, which ranged from the isoelectric point of normal apo A-I to a seven charge units more positive location, were largely influenced by the amount of dithiothreitol that was added to the samples for cystine reduction. This finding and the observations that apo A-I was immunologically colocalized with apo A-II in two of the IEF bands suggested the presence of an abnormal cysteine-containing apo A-I. Moreover, two-dimensional electrophoresis showed immunoreactivity with anti-apo A-I antibodies at a position that suggested a smaller molecular weight (data not shown).

For sequence analysis, five pairs of oligonucleotide primers were used to amplify the exons of the apo A-I gene with PCR. Direct sequence analysis, which gives simultaneous sequence information for both alleles, showed the homozygous loss of a guanine residue in codon 202 when compared with the wild type sequence of apo A-I (19-21). Double-dose signal intensity on Southern blots after hybridization of the genomic DNA of the patient with probes complementary to the amplified DNA fragment (prepared with oligonucleotides 7 and 10; see Fig. 3) largely excluded the possibility of a hemizygosity. Haplotype analysis was carried out using eight dimorphic restriction fragment length polymorphisms at the APOLP1 locus. As all family members had the same common haplotype, which is present with a frequency of 0.5 in the German population, no further support for the patient's homozygosity was obtained. However, the obligate heterozygotes, all of whom were pheno- typically heterozygous with respect to low HDL cholesterol (Table I), were shown to have the defective allele in common with the homozygote. This was determined by direct PCR sequencing and also by the loss of a Cel II restriction site caused by the deletion in codon 202 (Fig. 3). This deletion results in a shift of the reading frame. The mutant apo A-I contains 229 instead of 243 amino acids and residues 203-229 differ from the sequence of normal apo A-I. The charge difference between normal apo A-I and the mutant apo A-I is +7 , which is in agreement with the immunoblot result, and the molecular mass is $26,414 \mathrm{D}$ instead of 28,331 D for native apo A-I. The variant protein contains three cysteines, an amino acid that is absent from normal apo A-I.

The presence of cystein substantiates the above hypothesis that heterooligomer formation with other cysteine-containing proteins accounts for the multiple immunoreactive apo A-I bands on Western blots. To address this question more directly, the apo A-I band from the patient's plasma, which was at the IEF position of normal apo A-I, was electroeluted from the gel and subjected to UV-LDI-MS, a technique that allows the determination of molecular masses up to $250 \mathrm{kD}$ with an error of 1-4 per thousand. Masses of 8,820 D (a), 17,625 $\mathrm{D}(b)$, 26,490 D $(c)$, and 35,315 D $(d)$ were observed. They correspond to the masses expected for apo A-II monomer (a), apo A-II homodimer (b), mutant apo A-I (c), and apo A-II/mutant
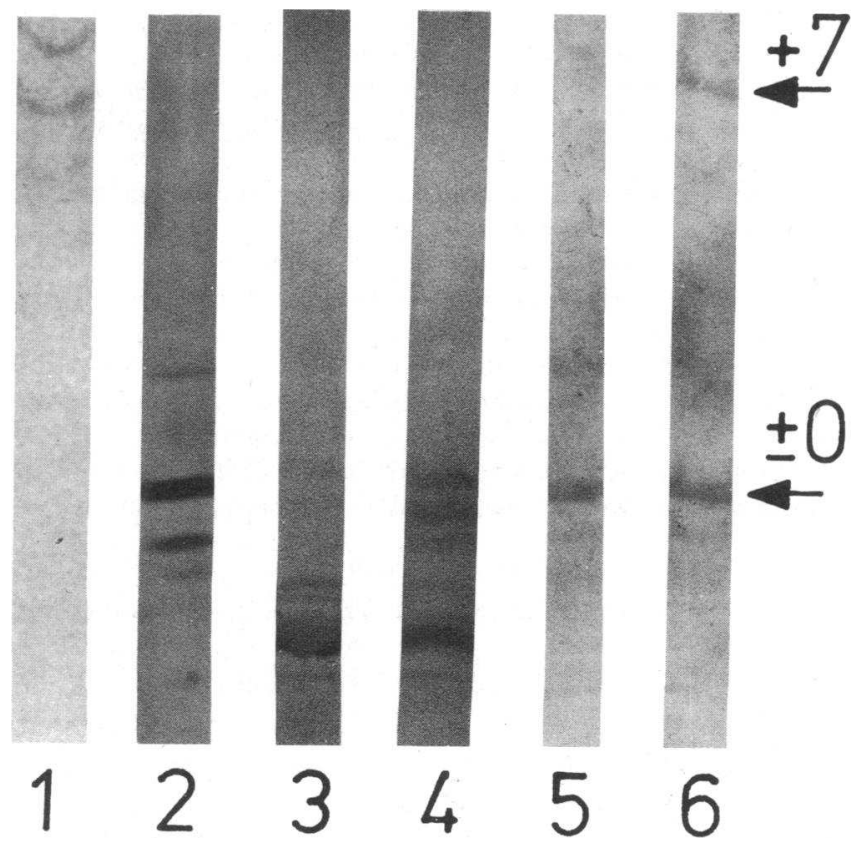

Figure 2. Characterization of the homozygous patient's apo A-I by IEF and subsequent immunoblot analysis. Immunoblotting of apo A-I (lanes 1, 2, 5, and 6) and apo A-II (lanes 3 and 4) subsequent to IEF of normal (lanes 2, 3, and 5), and the homozygous patient's plasma (lanes 1,4 , and 6 ) was done with (lanes 1 and 2 ) and without reduction (lanes 3-6). The isoelectric points of normal $( \pm 0)$ and variant apo A-I $(+7)$ are marked with arrows. Under reductive conditions (lanes 1 and 2 ), the variant apo A-I exhibited a relative charge difference of +7 compared with normal apo A-I. Under non reductive conditions, apo A-II and the mutant apo A-I were colocalized in the position of normal apo A-I (lanes 4 and 6). In heterozygous patients, no abnormal banding pattern for apo A-I was observed with the method used. 

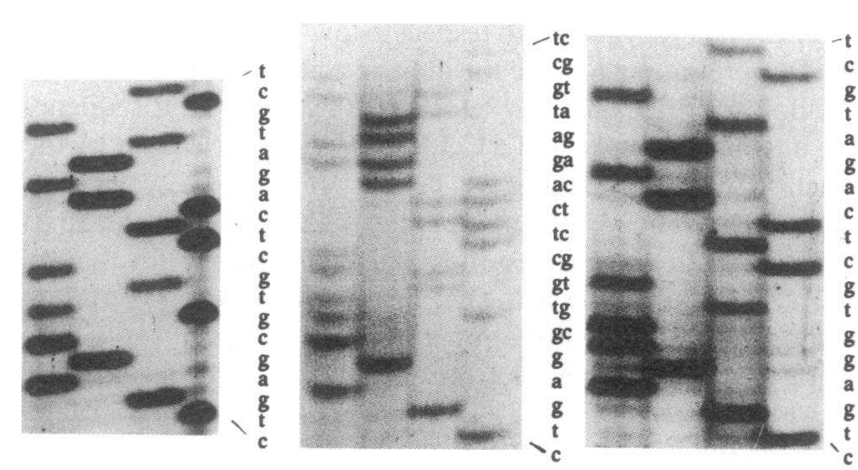

A

B
C
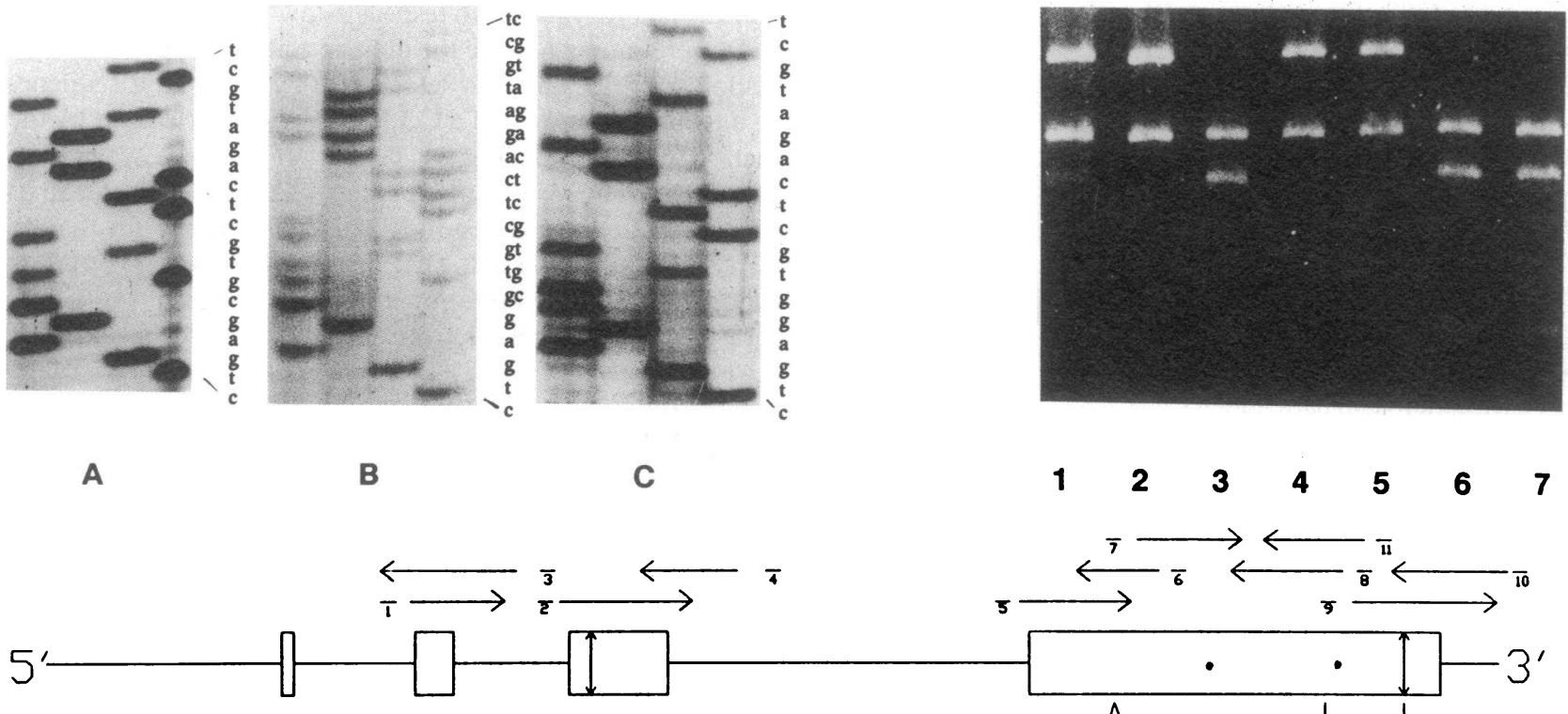

200

210

220

230

$\begin{array}{lllllll}1 & 2 & 3 & 4 & 5 & 6 & 7\end{array}$

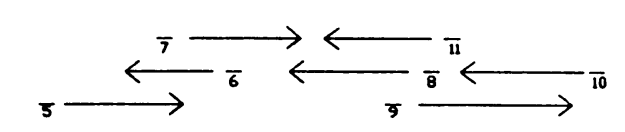

gagcatctragcacctcagcgagaaggccaagcccgcgctcgaggacctccgccaaggcctgctgeccgtgct ggagagct tcaaggtcagcttcctgagcgctctcgaggagtacactaagaagctcaacacccagtga

E H L S S T S A R R P S P R S R T S A K A C C P C W R A S R S A S END

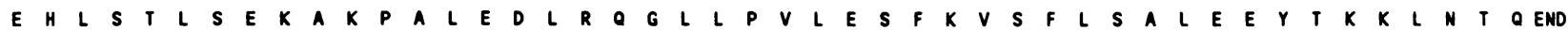

gagcatctgagcacgctcagcgagaaggccaagcccgcgctcgaggacctccgccaaggcctgctgcccgtgctggagagcttcaaggtcagcttcctgagcgctctcgaggagtacactaagaagctcaacacccagtga

Figure 3. A nucleotide deletion in the apolipoprotein A-I gene is the underlying defect in this case of HDL deficiency with corneal opacities. The figure shows a schematic drawing of the apolipoprotein A-I gene; exons are boxed, double-headed arrows inside boxes indicate start and end of sequence coding for the mature plasma form of apo A-I. Arrows above the boxes show the orientation and the length of sequence readings. Numbered bars behind the arrows indicate the location of the sequencing primers. Oligonucleotides used for PCR amplification were numbers $1-4,5$, and 10. The enlarged view of the carboxyterminus of the apo A-I gene (bottom) shows the site of the nucleotide deletion (black arrowhead) and the resulting amino acid sequence as well as the normal apo A-I sequence. Three cysteines that occur in the mutant sequence are boxed. Numbers on top of the sequence are amino acid residues of mature apo A-I. The region of the partial sequences shown in the upper left part are underlined. Sequence $A$ is from a normal individual, $B$ is from the patient's obligate heterozygous mother and shows the frameshift caused by the deletion of a $\mathrm{G}$ in codon 202 , and $C$ is from the homozygous patient. The upper right shows the transmission of the deletion using a Cel II restriction site as a marker, which is lost by the mutation. In the presence of the mutation a 497-bp fragment is seen, which is formed by the loss of the cutting site between 186-bp and 311-bp fragments. Also present is an invariate fragment of $360 \mathrm{bp}$. Lane 2 represents DNA samples from the homozygous patient, and lanes 1 and 3 from his mother and wife, respectively; lanes 4 and 5 are from DNA of his daughters, and lanes 6 and 7 are from random controls (blood for DNA from his son could not be obtained). Exon 1 of the apo A-I gene was not sequenced as the presence of the nucleotide deletion on both alleles had been established (see text). All exons of LCAT, including 120 bp of upstream sequence, were sequenced by the same approach.

apo A-I heterodimer (d) (Fig. 4). The calculated isoelectric point of apo A-II/mutant apo A-I heterodimers coincides with the one for normal apo A-I. Thus, it appears likely that the band at the position of normal apo A-I in the IEF gel represents such a heterodimer. The result of this analysis together with the other findings proves the presence in the plasma compartment of the mutant apo A-I (molecular mass 26,414 D) predicted from the gene defect and in addition rules out the presence of normal apo A-I.

Sequence identity of all exons, splice donor and acceptor sites, and $120 \mathrm{bp}$ of $5^{\prime}$ sequence of the LCAT gene of the homozygous patient with the wild type gene (22) largely reduced the possibility that a defective LCAT gene causes the observed phenotype.

\section{Discussion}

Decreased levels of plasma HDL, due to genetic as well as environmental factors, are related to a variety of lipoprotein and clinical abnormalities. Among the genetically determined HDL deficiencies, Tangier disease was the first to be identified and for many years the name was used synonymously for familial HDL deficiency. Tangier disease is characterized by the near absence of HDL from plasma, hepatosplenomegalia, orange coloured tonsils, and relapsing peripheral neuropathy (2). In recent years several cases of familial HDL deficiency have been reported that are different from Tangier disease. They have been classified by either their most prominent clinical or biochemical characteristics or by their underlying genetic defect. HDL deficiency with planar xanthomas (23), apo A-I/C-III deficiency (24), apo A-I/C-III/A-IV deficiency (25), and occasional cases of LCAT deficiency (3) have been associated with premature onset of congenital heart disease, while such an association has not been reported for $\operatorname{FED}(3,6)$, apo A-I $\mathrm{I}_{173: \text { Arg } \rightarrow \text { Cys }}$ (26), apo A-I $\mathrm{I}_{165: \text { Pro- }>\text { Arg }}(27)$, and HDL deficiency secondary to impairments of lipoprotein lipase activity (familial lipoprotein lipase deficiency; apo C-II deficiency) (28). The basic defects for apo A-I/C-III deficiency and apo A-I/C-III/A-IV deficiency 


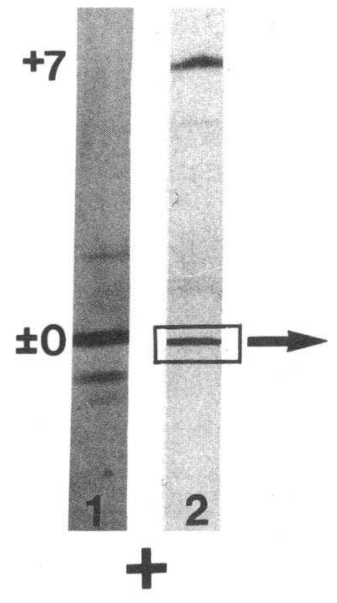

a

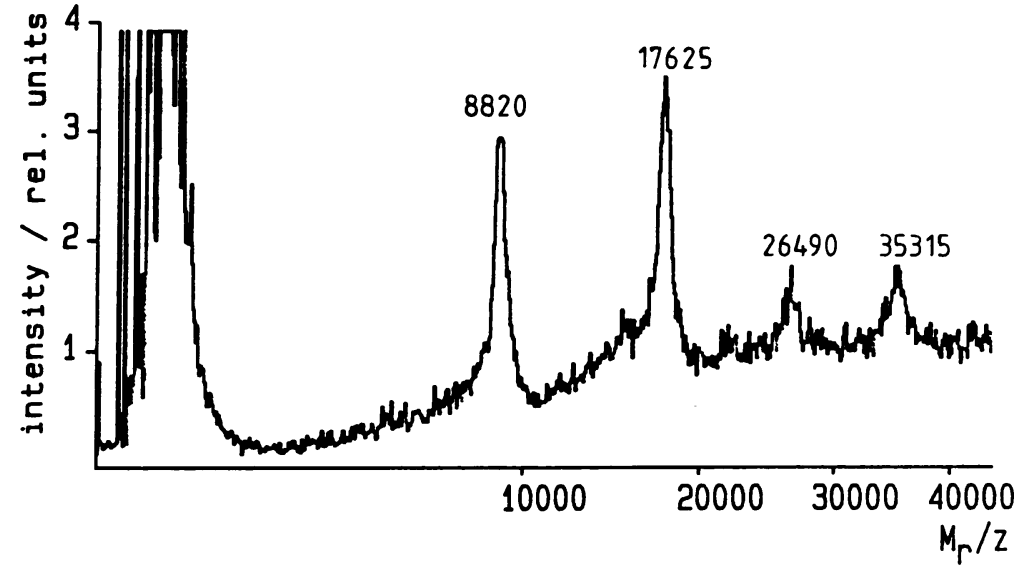

b
Figure 4. Mutant apo A-I forms heterodimers. Mass spectrometric

demonstration of apo A-II monomers $(\mathrm{m}=\mathbf{8}, 820$ D), apo A-II homodimers $(m=17,625 \mathrm{D})$, mutant apo A-I monomers (m $=26,490 \mathrm{D}$ ), and apo AII/mutant apo A-I heterodimers $(\mathrm{m}=35,315$ $D)$ in the homozygous patient's plasma. (a) Immunoblot of apo A-I subsequent to IEF of normal (lane 1) and homozygote plasma (lane 2). (b) UV-LDI-MS analysis of the protein focusing at the isoelectric point of normal apo A-I. have been identified as a DNA inversion including parts of the structural genes for apo A-I and apo C-III and a deletion of the complete apo A-I/C-III/A-IV gene cluster on chromosome 11, respectively $(29,30)$.

In this report we describe the identification of a homozygous base deletion in the fourth exon of the apo A-I gene as the basic defect in a patient with complete absence of HDL from plasma and corneal opacities. The conclusion that this mutation causes the observed HDL deficiency is based on the following findings: ( $a$ ) a clear gene dosage effect has been observed, since all heterozygote carriers of the base deletion show approximately half-normal HDL cholesterol concentrations, while the homozygous patient does not have detectable amounts of HDL; $(b)$ the possible existence of linkage disequilibrium between the deletion and another yet unidentified mutation was largely ruled out by sequencing the entire coding region of the homozygous patient's apo A-I gene, and the observation of apo C-III and apo A-IV on stained IEF gels and on Western blots in amounts that were not apparently different from those of normal probands; $(c)$ the presence of a functionally important mutation in parts of the gene responsible for its expression appears unlikely since the predicted gene product was detectable in plasma.

The familial HDL deficiency described here is distinct from previously reported cases involving a mutation. Most strikingly, apo A-I/C-III deficiency and apo A-I/C-III/A-IV deficiency are characterized by the complete absence of at least one additional apolipoprotein. Although the metabolic consequences resulting from these differences are not fully characterized, it is interesting to note that both apo A-I/C-III deficiency and apo A-I/C-III/A-IV deficiency are associated with low levels of plasma triglycerides (31). By contrast, in most other familial HDL deficiency syndromes hypertriglyceridemia was present. The case reported here, in which mild fasting hypertriglyceridemia is present, follows this rule and therefore provides additional evidence for an important role of apo C-III in the regulation of plasma triglyceride levels.

Another major difference between this and the two other disorders of the APOLP1 gene locus relates to the absence of premature coronary artery disease (CAD) in our patient. The onset of symptoms of CAD reportedly occured at age 25 and 31 in two female patients homozygous for apo A-I/C-III deficiency and at age 45 in the homozygous apo A-I/C-III/A-IV deficiency patient, also female. We cannot completely rule out the possibility that our patient who is free of symptoms at age 42 may still develop premature atherosclerosis. However, no CAD related death was reported to have occured in his family.

Cholesterol esterification rate, LCAT activity, and LCAT mass were found reduced in our patient. However, LCAT specific activity was unaffected, suggesting the presence of a functionally normal enzyme. Almost identical findings were made in apo A-I/C-III deficiency. The failure to isolate mutant apo A-I from the patient's plasma in amounts sufficient to study its interaction with LCAT in detail only allows us to speculate on the mechanism underlying reduced LCAT mass. One mechanism would place an important part of the activation properties of apo A-I in its carboxyterminal region. This hypothesis receives support from the finding that this region of apolipoprotein A-I is among the highly conserved parts of the molecule (32). Another possibility would be that the abnormal apo A-I does not allow the formation of a specific subclass of small size HDL particles that have been reported to be the preferred substrate of LCAT (3). Also, normal amounts of circulating HDL may be a prerequisite for the maintenance of regular LCAT plasma concentrations. Alternatively, enhanced catabolism of lipoproteins may have contributed to the decreased mass of LCAT.

Corneal opacities, which are the major clinical abnormality in our patient, are seen to some degree in the majority of homozygous HDL deficiencies. The massive extent of this condition in this disorder is, however, unusual since it is paralleled only by the finding in FED. Although the presence of abnormal lipoproteins and reduced LCAT mass are similar to FED, the condition described here is clearly distinct.

The pathophysiology of the way in which the genetic disorder described here leads to the unusual clinical and biochemical presentation cannot yet be predicted. In this context, it will be interesting to know whether the mutant apo A-I retains the function to interact with recognition sites that have been shown to trigger cholesterol excretion from cells (33-35). Weisgraber and co-workers have shown that apo E bound to HDL by disulfide-heterodimer formation with apo A-II is still capa- 
ble of binding to LDL receptors of fibroblasts (36). Therefore, it is intriguing to speculate that the presence of the mutant apo A-I even in minute amounts and on particles other than HDL may help maintain a basic level of reverse cholesterol transport that is sufficient to prevent CAD formation in our patient. The in vitro expression and isolation of apo $\mathrm{A}-\mathrm{I}_{202: \mathrm{fs}}$ in large quantities will therefore help us to gain important insights not only into the pathophysiology of this condition but may also help to classify HDL deficiency syndromes into harmful and innocuous entities.

\section{Acknowledgments}

We are indebted to all members of the described family for their interest and participation. We thank Thomas Terrahe and Marianne Opalka for help with the artwork.

for help with the artwork.

This research was supported by grants of H.F. and G.A. from Bundesministerium für Forschung und Technologie and from Landesversicherungsanstalt Westfalen. Grants to H.P. were from the Canadian Heart Foundation and the Canadian Medical Research Council.

\section{References}

1. Breslow, J. L. 1989. Familial disorders of high density lipoprotein metabolism. In The Metabolic Basis of Inherited Disease. C. R. Scriver, A. L. Beaudet, W. S. Sly, and D. Valle, editors. 6th ed. McGraw-Hill Inc., New York. 12511266.

2. Assmann, G., G. Schmitz, and H. B. Brewer, Jr. 1989. Familial high density lipoprotein deficiency: Tangier disease. In The Metabolic Basis of Inherited Disease. C. R. Scriver, A. L. Beaudet, W. S. Sly, and D. Valle, editors. 6th ed. McGraw-Hill Inc., New York. 1267-1281.

3. Norum, K. R., E. Gjone, and J. A. Glomset. 1989. Familial lecithin: cholesterol acyltransferase deficiency, including fish eye disease. In The Metabolic Basis of Inherited Disease. C. R. Scriver, A. L. Beaudet, W. S. Sly, and D. Valle. editors. 6th ed. McGraw-Hill Inc., New York. 1181-1194.

4. Glomset, J. A. 1968. The plama lecithin: cholesterol acyltransferase reaction. J. Lipid Res. 9:155-163.

5. Gordon, D., and B. M. Rifkind. 1989. Current concepts: high density lipoproteins-the clinical implications of recent studies. N. Engl. J. Med. 321:13111315.

6. Carlson, L. A., and B. Phillpson. 1979. Fish-eye disease. A new familial condition with massive corneal opacities and dyslipoproteinaemia. Lancet. 921923.

7. Frohlich, J., G. Hoag, R. McLeod, M. Hayden, D. V. Godin, L. D. Wadsworth, J. D. Critchley, and P. H. Pritchard. 1987. Hypoalphalipoproteinemia resembling fish eye disease. Acta Med. Scand. 221:291-298.

8. Friedewald, W. T., R. J. Lewis, and D. S. Fredrickson. 1972. Estimation of the concentration of low density lipoprotein cholesterol in plasma without the use of the preparative ultracentrifuge. Clin. Chem. 18:499-504.

9. Sandkamp, M., B., Tambyrajah, H. Schriewer, and G. Assmann. 1988. A simplified turbidimetric determination of apolipoproteins AI, AII, and B using a microtitre method. J. Clin. Chem. Clin. Biochem. 26:685-689.

10. Dobiasova, M. 1983. Lecithin: cholesterol acyltransferase and the regulation of endogenous cholesterol transport. Adv. Lipid Res. 20:107-144.

11. Frohlich, J., R. McLeod, P. H. Pritchard, J. Fesmire, and W. McConathy. 1988. Plasma lipoprotein abnormalities in hetrozygotes for familial lecithin: cholesterol acyltransferase deficiency. Metabolism. 37:3-8.

12. Albers, J. J., J. C. Adolphson, and C. H. Chen. 1981. Radioimmunoassay of human lecithin: Cholesterol acyltransferase. J. Clin. Invest. 67:141-146.

13. Menzel, H. J., R. G. Kladetzky, and G. Assmann. 1982. One-step screening method for the polymorphism of the apolipoproteins A-I, A-II and A-IV. J. Lipid Res. 23:915-922.

14. Towbin, H., T. Staehelin, and J. Gordon. 1979. Electrophoretic transfer of proteins from polyacrylamide gels to nitrocellulose sheets: procedure and some applications. Proc. Natl. Acad. Sci. USA. 76:4350-4354.

15. Saiki, R. K., S. Scharf, F. Faloona, K. B. Mullis, G. T. Horn, H. A. Erlich and N. Arnheim. 1985. Enzymatic amplification of $\beta$-globin genomic sequences and restriction site analysis for diagnosis of sicklecell anemia. Science (Wash. DC). 230:1350-1354.
16. Gyllenstein, U. B., and H. A. Erlich. 1988. Generation of single-stranded DNA by the polymerase chain reaction and its application to direct sequencing of the HLA-DQA locus. Proc. Natl. Acad. Sci. USA. 85:7652-7656.

17. Jabs, H.-U., G. Assmann, D. Greifendorf, and A. Benninghoven. 1986. High performance liquid chromatography and time-of-flight secondary ion mass spectrometry: a new dimension in structural analysis of apolipoproteins. J. Lipid Res. 27:613-621.

18. Karas, M., U. Bahr, A. Ingendoh, and F. Hillenkamp. 1989. Laser desorption/ionization mass spectrometry of proteins of mass 100000 to 25000 Dalton. Angew. Chem. Int. Ed. Engl. Suppl. 28.

19. Protter, A. A., B. Levy-Wilson, J. Miller, G. Bencen, T. White, and J. J. Seilhamer. 1984. Isolation and sequence analysis of the human apolipoprotein C-III gene and the intergenic region between the apo A-I and apo C-III genes. DNA (NY) 3:449-456.

20. Karathanasis, S. K., V. I. Zannis, and H. B. Breslow. 1983. Isolation and characterization of the human apolipoprotein A-I gene. Proc. Natl. Acad. Sci. USA. 80:6147-6151.

21. Sharpe, C. R., A. Sidoli, C. S. Shelley, M. A. Lucero, C. C. Shoulders, and F. E. Baralle. 1984. Human apolipoproteins A-I, A-II, C-II and C-III. cDNA sequences and mRNA abundances. Nucleic Acids Res. 12:3917-3932.

22. McLean, J., K. Wion, D. Drayna, C. Fielding and R. Lawn. 1986. Human lecithin-cholesterol acyltransferase gene: complete sequence and sites of expression. Nucleic Acids Res. 14:9397-9406.

23. Gustafson, A., W. McConathy, P. Alaupuvic, M. D. Curry, and B. Persson. 1979. Identification of apolipoprotein families in a variant of human plasma apolipoprotein A deficiency. Scand. J. Clin. Lab. Invest. 39:377-388.

24. Norum, R. A., J. B. Lakier, S. Goldstein, A. Angel, R. B. Goldberg, W. D. Block, D. K. Nofze, P. J. Dolphin, J. Edelglass, D. D. Bogorad, and P. Alaupovic. 1982. Familial deficiency of apolipoproteins A-I and C-III and precocious coronary heart disease. $N$. Engl. J. Med. 306:1513-1519.

25. Schaefer, E. J., J. Ordovas, S. Law, G. Ghiselli, L. Kashyap, L. Srivastava, W. H. Heaton, J. Albers, W. Connor, F. Lindgren, A. Lemeshev, J. Segrest, and H. B. Brewer, Jr. 1985. Familial apolipoprotein A-I and C-III deficiency. Variant II. J. Lipid Res. 26:1089-1101.

26. Franceschini, G., C. R. Sirtori, A. Capurso, K. H. Weisgraber, and R. W. Mahley. 1980. A-I Milano apoprotein. Decreased high density lipoprotein cholesterol levels with significant lipoprotein modifications in an Italian family. J. Clin. Invest. 66:892-900.

27. von Eckardstein, A., H. Funke, A. Henke, K. Altland, A. Benninghoven, and G. Assmann. 1989. Apolipoprotein A-I variants. Naturally occuring substitutions of proline residues affect plasma concentration of apolipoprotein A-I $J$. Clin. Invest. 84:1722-1730.

28. Brunzell, J. D. 1989. Familial lipoprotein lipase deficiency and other causes of the chylomicronemia syndrome. In The Metabolic Basis of Inherited Disease. C. R. Scriver, A. L. Beaudet, W. S. Sly, and D. Valle, editors. 6th ed. McGraw-Hill Inc., New York. 1165-1180.

29. Karathanasis, S. K., E. Ferris, and I. A. Haddad. 1987. DNA inversion within the apolipoproteins AI/CIII/AIV-encoding gene cluster of certain patients with premature atherosclerosis. Proc. Natl. Acad. Sci. USA. 84:7198-7202.

30. Ordovas, J. M., D. K. Cassidy, F. Civeira, C. L. Bisgaier, and E. J. Schaefer. 1989. Familial apolipoprotein A-I, C-III, and A-IV deficiency and premature atherosclerosis due to deletion of a gene complex on chromosome 11. J. Biol. Chem. 264:16339-16342.

31. Forte, T. M. A. V. Nichols, R. M. Krauss, and R. A. Norum. 1984 Familial apolipoprotein AI and apolipoprotein CIII deficiency. Subclass distribution, composition, and morphology of lipoproteins in a disorder associated with premature atherosclerosis. J. Clin. Invest. 74:1601-1613.

32. von Echardstein, A., H. Funke, M. Walter, K. Altland, A. Benninghoven, and G. Assmann. 1990. Structural analysis of 17 human apolipoprotein A-I variants: amino acid substitutions are nonrandomly distributed throughout the apolipoprotein A-I primary structure. J. Biol. Chem. 265:8610-8617.

33. Schmitz, G., A. Robenek, U. Lohmann, and G. Assmann. 1985. Interaction of high density lipoproteins with cholesteryl ester loaden macrophages: biochemical and morphological characterization of cell surface receptor binding endocytosis and resecretion of high density lipoproteins by macrophages. $E M B O$ (Eur. Mol. Biol. Organ.) J. 4:613-622.

34. Fidge, N. H., and P. J. Nestel. 1985. Identification of apolipoproteins involved in the interaction of human high density lipoprotein ${ }_{3}$ with receptors on cultured cells. J. Biol. Chem. 260: 3570-3575

35. Slotte, J. P., J. F. Oram, and E. L. Bierman. 1987. Binding of high density lipoproteins to cell receptors promotes translocation of cholesterol from intracellular membranes to the cell surface. J. Biol. Chem. 262:12904-12907

36. Innerarity, T. L., R. W. Mahley, K. H. Weisgraber, and T. P. Bersot. 1978. Apoprotein (E-A-II) complex of human plasma lipoproteins. II. Receptor binding activity of a high density lipoprotein subfraction modulated by the apo (E-AII) complex. J. Biol. Chem. 253:6289-6295. 